\title{
Prevention of Sudden Cardiac Death in Cricketers
}

\author{
1 John W Orchard, ${ }^{2}$ Rajesh Puranik, ${ }^{3}$ Christopher Semsarian, ${ }^{4}$ Jessica J Orchard, ${ }^{5}$ David Samra, ${ }^{6}$ Johan Duflou \\ ${ }^{7}$ Patrick Groenestein, ${ }^{8}$ Mark Young, ${ }^{9}$ Peter Brukner, ${ }^{10}$ Alex Kountouris
}

\begin{abstract}
Aims: Sudden death in cricketers is rare, with the most common causes being cardiac, neurological (head/neck trauma, mainly from ball impact) and environmental (e.g., lightning strike and heat stroke, the former which usually involves cardiac arrest). The aim of this study was to review possible prevention of sudden cardiac death and make recommendations.
\end{abstract}

Materials and methods: A literature review of possible causes of sudden cardiac death (SCD) among cricketers was performed, along with evaluation of evidence for existing preventative measures. The method for evaluation was expert panel (cardiology and sports medicine) consensus recommendations based on the published evidence base.

Results: Potential cardiac causes of sudden death while playing cricket can be divided into the following categories: (1) atraumatic-origin preexisting arrhythmias, cardiomyopathies and valve disorders (2) traumatic-origin arrhythmia (commotio cordis) (3) acquired coronary or valvular disease (4) viral myocarditis (5) Lightning strike. Preventive measures can be divided into pre-season (e.g., cardiovascular screening), prematch (e.g., assessment of viral illness), protective equipment (e.g., chest guards) and post-event (presence of first aid

${ }^{1,8}$ Sports Physician, ${ }^{2}$ Senior Lecturer, ${ }^{3}$ Professor, ${ }^{4}$ Lecturer ${ }^{5}$ Registrar, ${ }^{6}$ Pathologist, ${ }^{7}$ Cardiologist, ${ }^{9}$ Honorary Professor ${ }^{10} \mathrm{Head}$

${ }^{1}$ Sports Medicine, School of Public Health, University of Sydney New South Wales, Australia

${ }^{2}$ Sydney Medicine School, University of Sydney, New South Wales, Australia

${ }^{3}$ Agnes Ginges Centre for Molecular Cardiology, Centenary Institute, University of Sydney, New South Wales, Australia

${ }^{4}$ Charles Perkins Centre, School of Public Health, University of Sydney, New South Wales, Australia

${ }^{5}$ Sports Medicine, University of Sydney, New South Wales Australia

${ }^{6}$ Central Clinical School, University of Sydney, New South Wales, Australia

${ }^{7}$ Alfred Cardiology, New South Wales, Australia

${ }^{8}$ National Cricket Centre, Cricket Australia, Brisbane Queensland, Australia

${ }^{9}$ School of Allied Health, La Trobe University, Victoria, Australia

${ }^{10}$ Cricket Australia, Melbourne, Victoria, Australia

Corresponding Author: John W Orchard, Sports Physician Sports Medicine, School of Public Health, University of Sydney New South Wales, Australia, Phone: +61293518118, e-mail: johnworchard@gmail.com response including defibrillators). Our panel agreed that there was strong evidence that (1) trained and planned emergency response particularly with a defibrillator is effective at preventing SCD and (2) ceasing play in the presence of lightning strikes prevents lightning-related death (3) players with symptoms, risk factors or history suggestive of possible cardiac disease should undertake specific individual workup. There are other potential methods to prevent SCD, with expert level recommendations made in the absence of strong evidence.

Discussion and conclusion: The most controversial aspect of prevention of SCD is electrocardiogram (ECG) screening of asymptomatic players and this paper outlines the arguments both in favor and against without fully resolving the debate. The possible increase in early diagnosis of potentially life-threatening cases needs to be balanced against the risk of false positive results which may lead to discussion of exclusion from cricket. Cardiac workup is clearly of net benefit to symptomatic individuals (e.g. history of syncope, chest pain) or any player at higher than usual baseline risk (e.g., positive family history). Basic life support including access to defibrillators should be available with trained personnel wherever they can be afforded, which has strong evidence in favor of improving survival at the time of cardiac arrest.

Keywords: Arrhythmia, Coronary artery disease, Cricket, Defibrillator, Electrocardiograph, Genetics, Prevention, Screening, Sudden cardiac death.

How to cite this article: Orchard JW, Puranik R, Semsarian C, Orchard JJ, Samra D, Duflou J, Groenestein P, Young M, BruknerP, Kountouris A. Prevention of Sudden Cardiac Death in Cricketers. J Postgrad Med Edu Res 2016;50(2):49-58.

Source of support: $\mathrm{Nil}$

Conflict of interest: None

\section{INTRODUCTION}

Sudden cardiac death (SCD) is a tragic outcome for young people playing sport (athletes), their families and the entire community, resulting in many years of life lost. ${ }^{1}$ Although relatively rare, SCD is the leading cause of death for people playing sport. ${ }^{2}$ In the US, the rate is about 2 per 100,000 athletes per year ${ }^{3}$ which is reported to be 2.5-fold higher than that of the age-matched nonathlete population. ${ }^{4}$ However, this is much lower than the risk of 1 per 1000 per year in the general population (all ages) ${ }^{5}$ and definitions vary making international comparisons problematic. The population rate of SCD in young athletes appears to be fairly similar in Australia (population $=24$ million), with about 10 deaths per year. In Denmark, the rate of SCD in young athletes is reported to actually be lower than the general age-matched population. ${ }^{6,7}$ Despite 
exercise being a higher risk activity in the immediateterm for SCD, there is no doubting the paradox that exercise and physical activity reduces overall death rates, ${ }^{8}$ including in healthy people under the age of 35 years where the overall risk of SCD remains low. However, playing competitive sport may be a significant risk factor for young people with genetic (inherited) heart diseases, such as hypertrophic cardiomyopathy (HCM), and familial long QT syndrome (LQTS) that can lead to SCD without the athlete having any prior symptoms.

In most countries, asymptomatic athletes are not routinely screened for these conditions, which traditionally require a full 12-lead electrocardiography (ECG) (for arrhythmogenic abnormalities including long QT syndrome, Brugada syndrome and HCM) or an echocardiograph (for HCM and other cardiomyopathies). Both ECG and echocardiography are costly in a mass screening setting and are time-consuming. However, elite athletes in many sports are now routinely screened, although this is done more according to expert guidelines rather than a clear evidence-based approach that the benefits of screening exceed the risks.

There is some evidence of increased risk of SCD during sport in Australian indigenous populations. For example, one study by Young et al reported that between 1982 and 1996, the estimated incidence of SCD (related to ischemic heart disease) among Aboriginal Australian football players in the Northern Territory was 19-24 per 100,000 player/years: a high figure compared with a reported incidence of 0.54 per 100,000 player / years among Australian Rules Football players of similar ages in Victoria. ${ }^{9}$ There is currently no widespread screening program in Australia, the country of origin of the authors of this paper. The Australasian College of Sports Physicians (ACSP) position statement recommends screening with a 12-lead ECG and history and physical examination for elite athletes only, but notes that indigenous populations should be prioritized. ${ }^{10}$ This ACSP position statement does note that screening and particularly mandatory exclusion from sport for asymptomatic but positive cases should not be enforced. The England and Wales Cricket Board (ECB) conducts a cardiac screening program for their contracted players. ${ }^{11}$

Previous reviews of prevention of SCD in sport have been written, 12,13 although the focus is generally on sports with moderately high or greater risk, such as football. ${ }^{14-16}$ Cricket is current listed in category 1A (the most sedentary of all sports, along with billiards, golf, and shooting) by a Bethesda Conference Taskforce which attempted to categorize sports by cardiac risk. ${ }^{17}$ Cricketers in Australia collectively have an overall rate of SCD during cricket of 2 per $100,000^{18}$ which is similar to other sports, although this rate has a different distribution to higher risk sports. That is, cricket almost certainly has a lower rate of SCD in junior players than more intense sports, such as the football codes, but a higher percentage of players aged over 35 years which increase the overall rate of SCD. ${ }^{18}$ The discussion of the Bethesda Conference Taskforce emphasised that there could be variation by position and level and that risk classification should not be seen as rigid. For example, a spin bowler playing a low standard of cricket may truly be in this lowest cardiac risk stratum, but a fast bowler playing at international level would presumably have a higher risk, equivalent at the very least to sports, such as baseball. However, the reality that cardiac output in cricket is lower than that of football codes, basketball, rowing and other high intensity sports does affect the risk to benefit ratio of screening. False positives and inconclusive ('gray') results are considered the major downside of screening (including inadvertent but unnecessary anxiety, invasive follow-up tests and procedures and even lifetime exclusion from sport).

\section{MATERIALS AND METHODS}

A review of possible causes of sudden cardiac death among cricketers of all ages was performed, both of the scientific literature via PubMed and general publications via Google. Causes of death that involved cardiac arrest as the specific cause of death were included as part of this review, including traumatic (commotio cordis), following lightning strike and secondary to myocarditis due to viral illness. Causes of death that were not included as part of this review included heat stroke, vascular pathology (e.g., venous thromboembolism) or vascular trauma outside the cardiac system (e.g., traumatic vertebral artery dissection).

For each of the possible causes of cardiac death, an evaluation was made of the evidence for existing preventative measures. The method for evaluation was expert panel review and agreement to form recommendations. The panel consisted of three cardiologists (RP, CS, PG), three sports physicians (JWO, MY, PB), a sports medicine registrar with emergency training (DS), a physiotherapist/cricket administrator (AK), a public health lawyer / cardiac researcher (JJO) and a forensic pathologist (JD). The conclusion and recommendations made were categorized in a binary fashion as unanimous (consensus) recommendations (i.e., where there was strong evidence) or qualified panel recommendations (i.e., low-moderate expert evidence that was not fully established according to published evidence).

\section{RESULTS}

The potential cardiac causes of sudden death while playing cricket can be divided into the following categories: 
- Acquired (atherosclerotic) coronary heart disease

- Arrhythmias (a) atraumatic-origin (congenital/preexisting), (b) traumatic-origin arrhythmia (commotio cordis), (c) arrhythmia due to lightning strike.

- Cardiomyopathies

- Viral myocarditis

- Valve disorders.

\section{Atherosclerotic Coronary Heart Disease}

The most frequent category of SCD in cricket is due to acquired coronary heart disease, which in the overwhelming number of cases is due to coronary artery atherosclerosis and its various complications. This is particularly a risk in players over the age of $35,{ }^{19}$ although it can occur before this age.

Recommendation 1: (Strong evidence-based consensus)-All players with suspicious symptoms (e.g., chest pain, shortness of breath, syncope or pre-syncope on exercise; palpitations), examination findings worthy of further investigation (e.g., high blood pressure, heart murmur) or family/past history of significant cardiac disease or sudden death should have a specialist cardiology workup.

Recommendation 2: (Strong evidence-based consensus)There is strong evidence that cardiac defibrillators can improve survival after cardiac arrest. ${ }^{5,20}$ Cardiac defibrillators (Figs 1A and B) are, therefore, one of the best methods for prevention of sudden death and should be implemented where budget allows. ${ }^{21,22}$ When installed and used in conjunction with emergency plans at major sporting venues, high survival rates from cardiac arrest can be demonstrated. ${ }^{23}$

Recommendation 3: (Strong evidence-based consensus)Emergency response is also not limited to purchase of cardiac defibrillators. ${ }^{5}$ All of the following factors contribute to best possible response: (1) regular first aid/ CPR training for staff members, such as umpires and

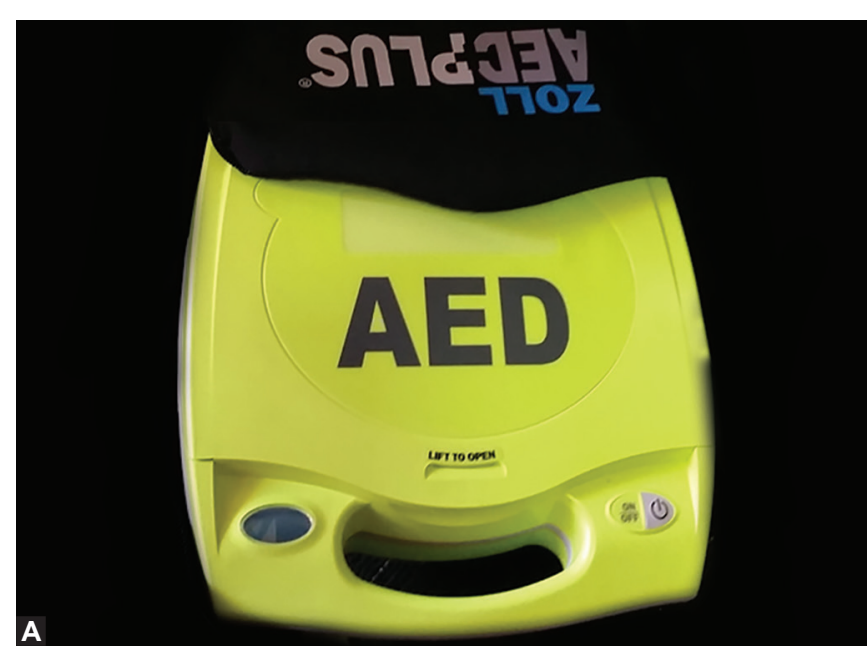

players, (2) pre-event check of facilities and equipment (medical time out, see Appendix) (3) venue layout planning to optimize ambulance access and best possible response (e.g., medical room in close proximity to playing field), (4) preparation of written emergency response plan being clearly posted at playing and training venues, (5) an appropriately located and clearly signposted defibrillator allowing it to be readily accessible to sports participants.

Recommendation 4: (Majority expert view)-There is some evidence that use of performance-enhancing drugs can increase the risk of $\mathrm{SCD}^{24}$ so their use must be discouraged (as is the current stance of world anti-doping agency (WADA)-affiliated sports like cricket). Although high quality trials are hard to conduct, there is evidence from case series reports that performance-enhancing drugs, such as blood boosting products, stimulants and anabolic agents can increase the risk of SCD. ${ }^{24,25}$ The sport of cycling, which has been associated with a high incidence of doping, also has a higher than expected rate of sudden death, notwithstanding that it is also in the highest risk category 3C with respect to cardiac output. ${ }^{17}$

Recommendation 5: (Strong evidence-based consensus) General risk factors that apply to the population also apply to cricketers, particularly those aged over 35 years who are entering the age bracket for which acquired coronary heart disease is a foreseeable condition. The risk factors to avoid, if possible, include smoking, inactivity (which is a net risk factor for SCD) ${ }^{4}$ hypertension, ${ }^{26}$ high blood lipids, obesity, poor diet and poorly controlled diabetes.

\section{Congenital or Preexisting Arrhythmias, Cardio- myopathies or Valve Disorders}

In younger players ( $<35$ years old), preexisting or congenital conditions are possible causes of sudden death. Some of these are arrhythmias (long QT syndrome,

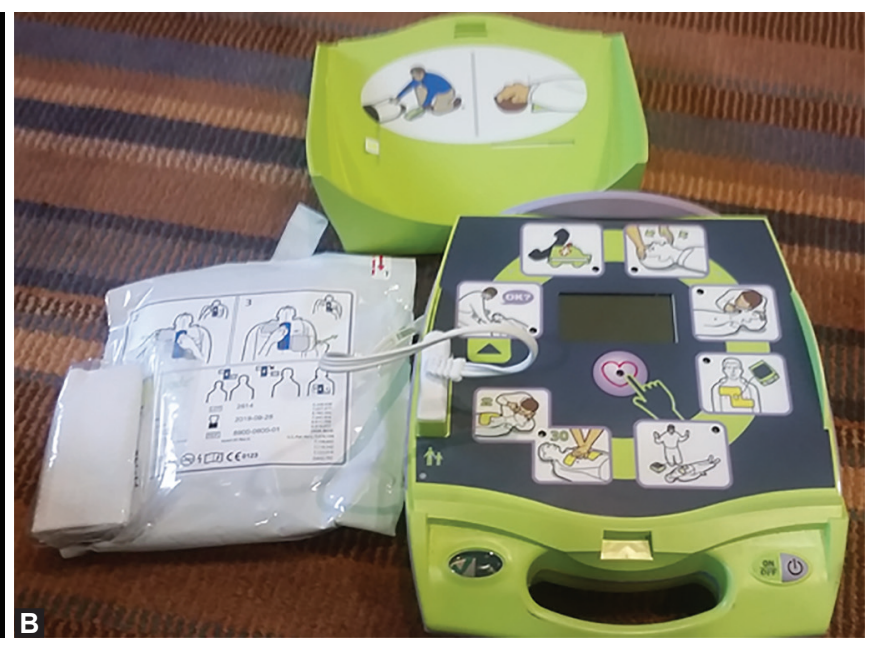

Figs 1A and B: A cardiac defibrillator closed and opened 
Brugada syndrome), while some are cardiomyopathies (the most common being hypertrophic cardiomyopathy). ${ }^{1}$ Some of these conditions may give rise to prodromal symptoms although there are cases of sudden death without any previous symptoms. Consideration of routine cardiac workup for high-level asymptomatic young athletes is one of the most controversial topics in sports medicine and cardiology at the current time. ${ }^{27-33}$

All of recommendations 1, 2, 3, 4 and 5 also apply to the category of preexisting cardiac conditions.

Our panel of experts undertook vigorous debate about the evidence-base and merits of screening of asymptomatic low-risk elite athletes (as opposed to workup of symptomatic or higher-risk elite athletes for which there was universal agreement). With respect to the evidencebase for the effectiveness of screening at preventing SCD, the most compelling study has been conducted in Italy, demonstrating reduction of SCD risk after a compulsory screening program. ${ }^{34}$ However, this study may not be applicable to a cricket population for the following reasons:

- The most-common sport played in Italy is football (soccer) which almost certainly has higher risk of SCD than cricket. ${ }^{17}$

- There may be a racial predisposition to higher risks of hypertrophic cardiomyopathy and arrhythmogenic right ventricular cardiomyopathy in the Italian population, making ECG screening in this environment more effective than in other environments. ${ }^{35}$

- The success of the Italian program may have been dependent entirely on quite rigid mandatory exclusion from sport ( $2 \%$ of screened athletes were forbidden from playing sport due to abnormal results), ${ }^{34}$ a strategy which may not be acceptable or justified in the lower-risk sport of cricket.

There are other populations in which cardiac screening has not lowered the death rate, such as Israel ${ }^{36}$ (where like Italy it has been mandatory for athletes to be screened). There are nations in which a decision against cardiac screening has been made because the baseline risk of athletes is considered to be lower than the general population, and hence mandatory exclusion would not put the athlete into a lower-risk group. ${ }^{6,7}$ Some authors have argued that mandatory screening should be only instituted for high-risk sports, ${ }^{37}$ which would exclude cricket as a lower-risk sport. Others have suggested mandatory cardiac screening should be country-specific, depending on the genetic mix and predisposition of the population. ${ }^{38}$ Some of the abnormalities found on screening, such as high-risk hypertrophic cardiomyopathy would be grounds for exclusion from high-risk sports but would not be grounds to exclude an athlete from playing a sport, such as cricket. ${ }^{39}$
Despite a lack of "evidence-based" research to insist on screening of asymptomatic cricketers, there is a strong pragmatic argument in favor of screening. Sudden cardiac death is perhaps the most common potential cause of death in cricketers and a foreseeable (if only miniscule) risk. For a well-resourced professional organization, there is a perceived need to have been seen to have taken every possible step to reduce this risk. Therefore, even if the effectiveness of screening is not proven, an argument follows that screening may be an effective preventive measure and this opportunity should not be missed.

It has been established that if cardiac screening of asymptomatic cricketers is to be undertaken, then a 12-lead ECG should be included and specialist sports cardiologists should interpret the findings, as both of these measures vastly improve sensitivity and specificity if diagnosis compared to basic history and examination screening. ${ }^{40}$

There is a current lack of published data comparing risk of SCD in cricket to age- and race-matched general population or results of cardiac screening programs in cricket. Further published results may change evidencebased recommendations regarding screening of asymptomatic cricketers.

Recommendation 6: (Majority expert view)-The decision on routine screening of asymptomatic elite cricketers at baseline (low) risk can be made collectively by the medical staff, players and administrators of each cricket organization after review of the evidence and local situation (e.g., racial mix of players, availability of specialist sports cardiology facilities, insurance coverage). One option is to explain to asymptomatic players the benefits (potential to uncover an occult but life-threatening cardiac condition) and risks (potential to inadvertently and unnecessarily restrict participation in cricket due to test results) to each individual player and allow an individual decision on screening. If screening is undertaken, at a minimum it should include 12-lead ECG.

Cricket, having a lower cardiac risk than many other sports, ${ }^{17}$ also has poor epidemiological documentation on the actual risk of sudden cardiac death. Another contributor to the thin knowledge base is the lack of registries in the countries where cricket is most popular, particularly in South Asia. ${ }^{41}$ Some Indian subpopulations have been documented as having genetic predisposition to cardiomyopathy. ${ }^{42}$ The total rate of SCD in the young Indian population is not well-documented, let alone the sport-specific rate for cricket. This makes it difficult to judge whether screening of asymptomatic young cricketers in India would be likely to save lives or not, an important distinction given the known negatives of false positives and inconclusive tests. It is presumed 
that one of the reasons for a high-risk of sudden cardiac death in professional basketball is the high proportion of players of African descent. This may be relevant to cricket teams in South Africa, Zimbabwe and the West Indies, if it was found that cricketers of African descent were also at higher-risk.

Recommendation 7: (Majority expert view)-Registries of SCD are encouraged in all cricket-playing nations to assist in determining the extent of this phenomenon, and hence the likely potential value of cardiac screening of asymptomatic players.

\section{Infective Myocarditis}

Another possible cause of SCD is infective (usual viral) myocarditis. ${ }^{43}$ This is certainly recognized as a possible cause of death in higher-risk activities, such as marathons, triathlons and iron man events. There is strong advice in these events to avoid competition on occasions where a competitor has a febrile illness, which maybe the only clinical manifestation of myocarditis. It is unknown how significant the potential risk increase is for cricket. Cricket is also unique among team sports being often played over multiple days and without allowing full substitutes for players. It would be problematic to completely exclude all febrile players from play in multi-day games on all occasions.

Recommendation 8: (Majority expert view)-Cricketers who are unwell with fever should be medically assessed before being cleared to return to play. Illness with high fever $\left(>38^{\circ} \mathrm{C}\right)$ or fever in association with symptoms or signs which could involve the cardiac system (chest pain, shortness of breath, dizziness, palpitations, heart murmur) should be absolute contraindications to participation in all sport, including cricket.

\section{Commotio Cordis}

Cricket is one of the sports which presents a risk for commotio cordis (cardiac arrest from arrhythmia after direct blow to the chest wall), particularly in junior players. ${ }^{44}$ There have been previously described cases and even deaths in high level players. ${ }^{45}$ The rate of commotio cordis in cricket appears to be lower than that in baseball because the ball is in proximity to the chest less often. ${ }^{46}$

The major recommendation to prevent against death is again good emergency response including availability of a defibrillator.

Recommendation 9: (Majority expert view)-Chest guards are often considered as a potential method for protection against commotio cordis. In theory, they could reduce the incidence of this condition, but there is insufficient evidence to demonstrate that this actually is the case. ${ }^{47-49}$ There are certainly recorded cases (e.g., up to $40 \%$ ) of commotio cordis that have occurred despite the use of chest protectors. ${ }^{50}$ Chest guards of configurations used to date cannot be recommended as routine protective equipment in light of lack of supportive evidence. However, further research on the potential protective role of chest guards could be undertaken. Given that the risk of commotio cordis is higher in baseball than cricket, ${ }^{46}$ this is the sport where such research is more likely to prove any possible risk reductions.

Recommendation 10: (Majority expert view)-There is also a small risk of suffering commotio cordis at training sessions as well as matches. A risk factor, in theory, at cricket net sessions, is a player or spectator being struck by a ball that he or she does not pay due attention to. Cricket "net" training sessions should, therefore, be conducted in a setup which reduces the risk, as much as possible, of other persons (besides the net batsman and bowler, who are giving attention to the ball used in that particular net) being struck by a ball of which they are unaware.

Softer baseballs have been proposed and are used to prevent commotio cordis in very young baseball players. ${ }^{51}$ In cricket, very young players will often learn to play with a tennis ball which would probably have a similar or even greater protective effect, although this has not specifically been studied to our knowledge.

\section{Lightning Strikes}

Lightning strike is an under-recognized but clear danger in certain sports, including cricket. ${ }^{52}$ It is a risk in all countries of the world, although certain countries (like South Africa) have higher-risk than others. There is a common misconception that lightning strikes only occur during rain; in fact lightning strikes can and do occur when it is not raining, and this may make cricket particularly susceptible, as there could be a prevailing view that rain-rules for cricket may in themselves be protective. There have been multiple deaths recorded due to lightning strikes in cricketers in Australia during the previous decade and in past years. ${ }^{18}$ There has been a recorded case of two cricketers in the same first-class game in Jamaica ${ }^{53}$ being struck by lightning and fortunately neither was seriously injured. Disturbingly the game was not stopped after the first lightning strike because it was not raining. ${ }^{53} \mathrm{We}$ are unaware of any recorded case of lightning strike in a major stadium with complete grandstand coverage around the perimeter of the ground. A ground, such as Etihad Stadium, Melbourne (home ground of the Melbourne Renegades in the Big Bash League, with a retractable roof) would be totally immune to lightning strike with the roof closed and is possibly completely safe even with the roof open, due to the small aperture that lightning may be unable to penetrate. That is, if the 
shortest route of lightning to the earth was always via the overhanging grandstand roofs rather than via the earth/ players on the pitch, then the risk would be effectively zero. To our knowledge, it is not established, however, whether the circumferential presence of grandstands confers absolute immunity to lightning strike on major playing fields or whether this occurrence has not yet been reported because only a limited number of games are played at stadiums in this category.

Recommendation 11: (Strong evidence-based consensus)-Cricket is a sport where risk of sudden death by lightning strike is real even in situations where it is not raining. In the absence of more sophisticated monitoring or stadium assessment, at amateur level cricket should generally adopt the 30/30 Lightning Rule (suspend play if a lightning strike occurs within 30 seconds of thunder and do not recommence until 30 minutes after the last observed lightning strike). ${ }^{52}$ At lower levels of the game, off-field officials and even spectators should have the ability to influence the $30 / 30$ rule (i.e., alert umpires for the need to suspend of play) rather than rely only on the on-field umpires, whose duties on the field may prevent them from acutely observing and counting seconds around lightning.

Recommendation 12: (Majority expert view)-The 30/30 rule can be waived or modified at the professional level of the game in the following circumstances:

- In stadiums where there is an enclosed roof, in particular, or circumferential coverage of grandstands providing an effective shelter for players and spectators, it may be possible to modify the 30/30 lightning rule. However, recommendations regarding lightning safety for such venues should be provided by a structural building engineer or meteorologist expert in lightning safety.

- If real time professional weather coverage is provided during games to a level of accuracy where the exact presence of lightning and its direction is known within less than a kilometer, then the realtime service can be charged with the duty of when to suspend play (i.e., when lightning is imminently approaching the stadium) rather than the more conservative 30/30 rule (i.e., when lightning is somewhere in the vicinity of the stadium, irrespective of its exact location and direction). Such a service is costly but potentially appropriate at professional level, whereas the more gross and conservative tool of the $30 / 30$ rule is more realistic as a safety measure at amateur level.

\section{DISCUSSION}

Preventive measures can be divided into pre-season (cardiovascular screening), pre-match (assessment of viral illness), protective equipment (chest guards) and post-event (presence of first aid response including defibrillators). With respect to prevention of SCD in sport, optimal emergency response is critical to reducing number of deaths, ${ }^{20}$ given that prediction of cardiac arrest is an inexact science. If best practice emergency response is available (including rapid onset of CPR and early defibrillation), ${ }^{21}$ then survival rates are much higher than less rapid response. Defibrillation can be potentially effective in many of the potential causes of cardiac arrest in cricket, including acquired coronary occlusion, preexisting or viral cardiomyopathy, arrhythmia, commotio cordis and even after lightning strike. Therefore, purchase of defibrillators for cricket grounds should be a priority (e.g., www.projectdefib. com.au) as it should be for all sporting venues.

The sporting environment also needs regular safety checks and review of practices to make sure that in the unlikely event of an emergency that there is adequate preparation. Whereas hospital, emergency department and ambulance staff will routinely encounter cardiac arrests; in sporting environments the events are rare enough that many team physicians or physiotherapists might only witness such an event at a sporting ground once or twice in their career, if at all. Regular emergency medicine refresher courses for staff, physical checks that all equipment is in place and routine pre-game medical meetings and checks before the start of play can help make the best possible response likely for a very unlikely event. A good analogy is the safety check and demonstration at the start of a plane flight, which is accepted by passengers and crew alike despite the intentions that hopefully none of them will ever be involved in an emergency evacuation of the plane.

Electrocardiogram investigation in cricketers is likely to provide helpful information that may possibly (but not certainly) decrease the risk of sudden cardiac events. This needs to be balanced against the risk of false positive/inconclusive results, and hence is of most value in those symptomatic individuals (e.g., history of syncope) or any player at higher than usual baseline risk (e.g., positive family history). It is also very important to have ECGs read by someone with expertize in interpreting athletes' ECGs. Recent improvements to ECG interpretation (particularly the 'Seattle Criteria') ${ }^{2}$ for athletes have significantly improved the sensitivity and specificity of 12-lead ECG screening, particularly in identifying abnormalities leading to a later diagnosis of HCM. Greater numbers of expert panels are recommending routine ECG ( \pm echocardiogram) for screening of asymptomatic young athletes. The detection rate of formal cardiac screening is very likely to be elevated in the sporting environments which are the highest risk (e.g., NBA basketball, Olympic triathlon, cycling and rowing, UEFA level football). Some 
racial groups are known to have a higher risk of cardiac abnormalities (e.g., African-American males). However, it is unknown whether any of the racial groups playing cricket are at high enough risk in a slightly lower-risk sport, such as cricket to make the benefits of screening outweigh the risk of false positives. As background risk of SCD decreases, Bayes theorem dictates that not only does the number of true positives decreases, but the number of false positives also rises.

Elite cricket is perhaps rated too low in Bethesda Taskforce 8 category $1 \mathrm{~A}^{17}$ but nonetheless is certainly lower risk than the sports previously listed. Some experts in cricket would already advocate routine screening (for example the England and Wales Cricket Board already mandates routine ECG screening for contracted players). ${ }^{11}$ However, it would be premature to claim that there was an evidence-based argument compulsory screening as the true rate of both SCD in asymptomatic elite cricketers and false positive ECGs in this population are not known. There are also precedents from areas like population based PSA testing for prostate cancer where screening was initially advocated as it was thought to be in the category of "unlikely to be of any harm" when evidence now is that it probably of net harm. ${ }^{54}$ Even cardiac screening for the middle-aged person prior to an exercise program was previously embraced but is now thought to be as potentially harmful as helpful. That is, the benefits of exercise are so strong that any screening that might lead to less exercise being undertaken could paradoxically put a person into a higher cardiac risk category.

There may be further advances in treatment of cardiac conditions in cricketers on the horizon. Modern affordable and highly portable devices (e.g., rhythm strip devices attached to smart phones that can give readings within 30 seconds) have the potential clinical applications of an on-field portable event-recording device, e.g., for a player suffering dizziness during play, with much quicker access to a rhythm strip output (e.g., including on the actual playing field, Figs 2A and B) than even a sideline ECG. Therefore, assessment of cardiac rhythm in situations of non-specific symptoms (e.g., dizziness) may soon be feasible even on the field. Players with more specific symptoms on-field (e.g., chest pain, palpitations) should still immediately come off the field for comprehensive medical care.

Despite the many other possible preventive measures (Fig. 3), it is important to emphasize that primary prevention of cardiac disease and the availability of early defibrillation in the emergency setting are the most established methods of preventing SCD. Basic life support including access to defibrillators should be available with trained personnel wherever they can be afforded. For levels of cricket where medical personnel are not present, first aid courses including defibrillator use are recommended for players and officials.

\section{APPENDIX: POSSIBLE AGENDA FOR PRE-MATCH MEDICAL SAFETY MEETING}

Communication check: Officials at the match responsible for safety should meet to check what communication can be made among them and externally in the event of an emergency. The nearest hospitals and their phone numbers along with ambulance phone number should be known.

Facilities check: The location of the following items (if present) must be pointed out in sequence and someone must confirm that they have checked that they are operational that day. Those present should state whether they have had recent training in the use of each item:

- Defibrillator(s) - Including one which is dedicated to on-field personnel (if in a large stadium) and which has had a battery check at the start of the game.

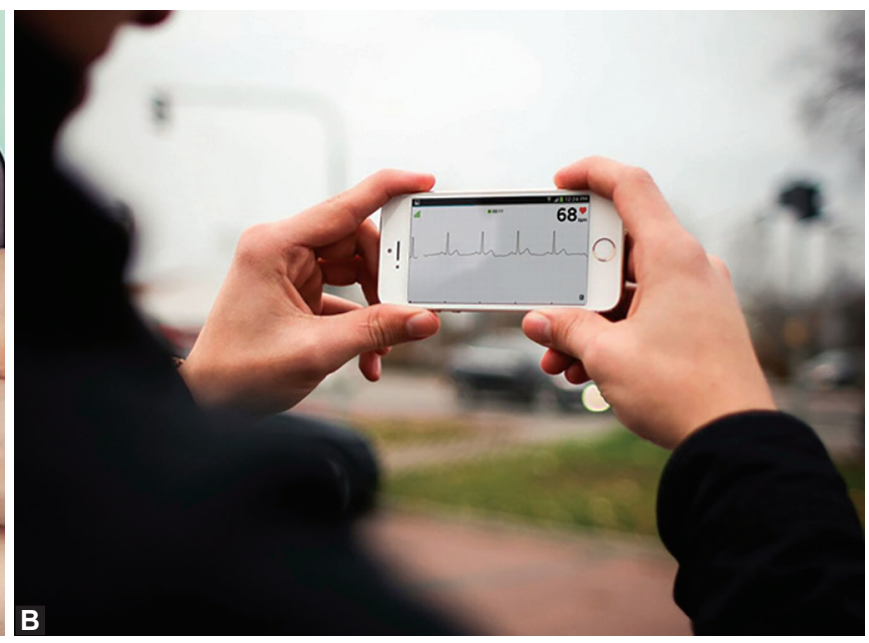

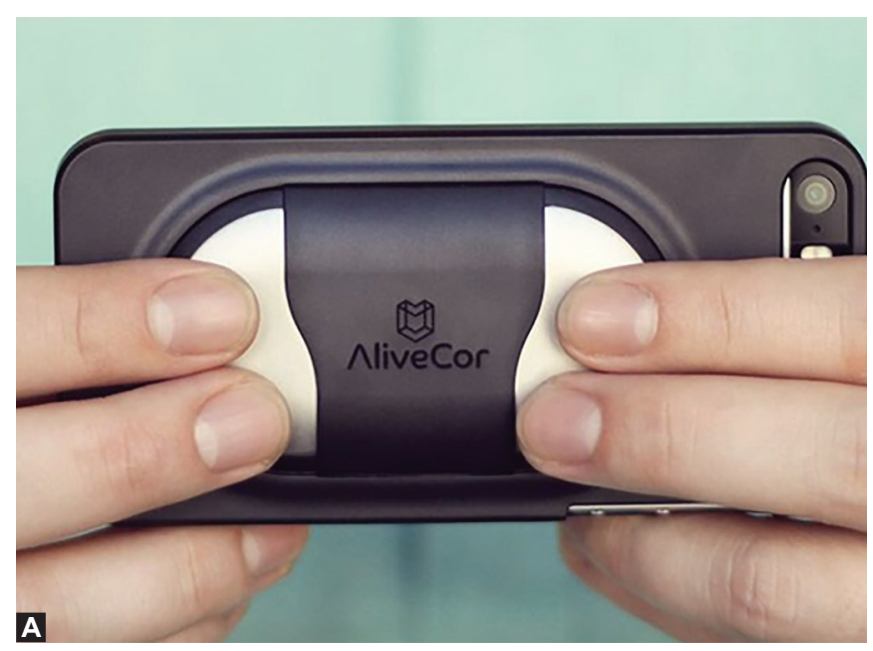

Figs 2A and B: Taking a reading on the AliveCor Mobile ECG device 


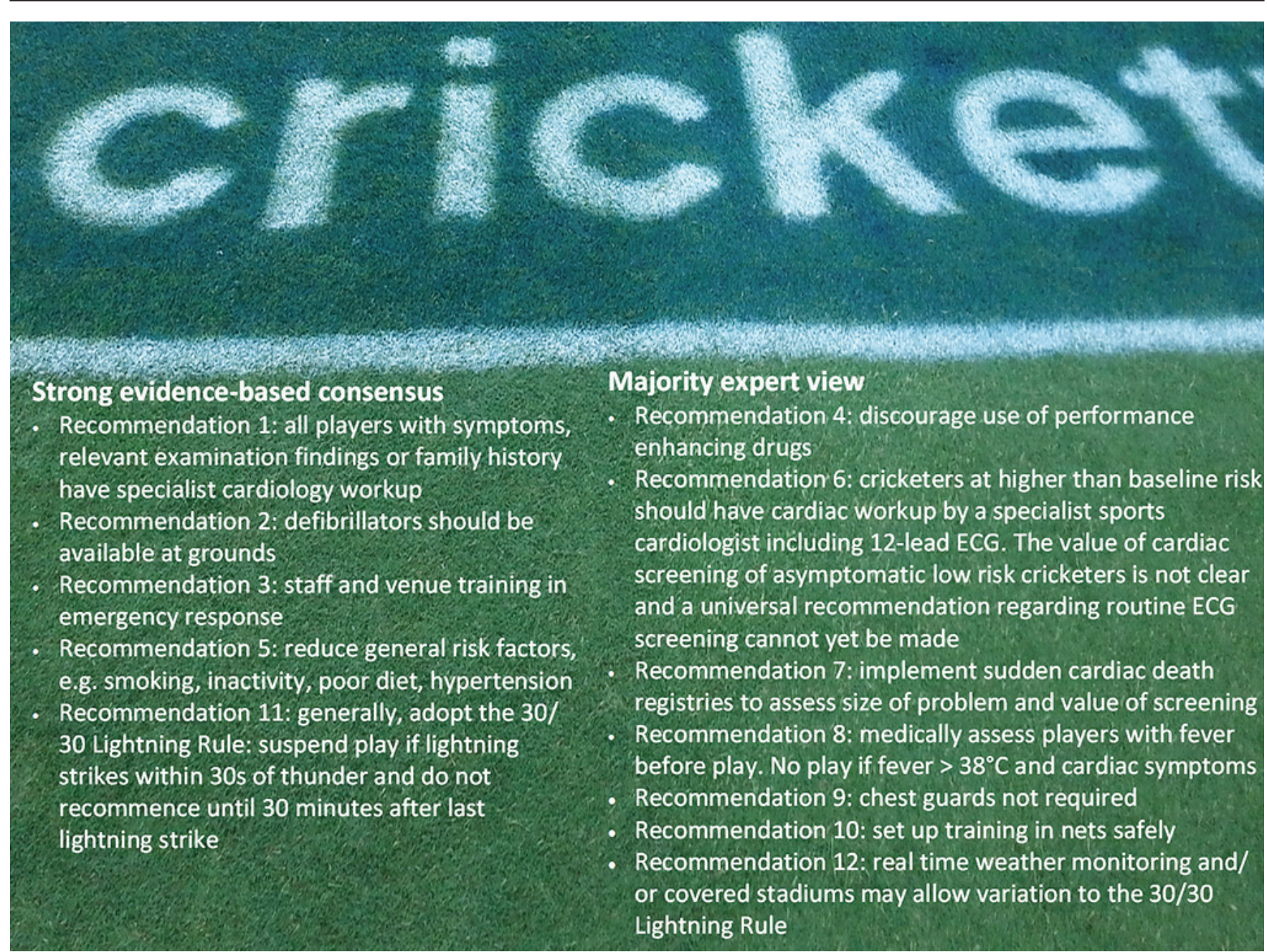

Fig. 3: Recommendations of the expert panel to prevent sudden cardiac death in cricket

- Oxygen cylinder, regulator and oxygen mask, along with giving bag set, which can be easily turned on (usually set in off position to prevent leak).

- Stretcher and neck collar (or motorized vehicle at high level games).

- Medical bag (if doctor present) with check for adrenaline/epipen, asthma inhaler, glucose injection, antiepileptic drugs, IV fluids.

Special needs check: One representative from each team should alert if there are any players who are at higher-risk of requiring emergency intervention. This may include any player who:

- Is asthmatic

- Is diabetic

- Is epileptic

- Is pregnant (for female athletes)

- Has a history of anaphylaxis (e.g., peanut allergy) that requires epipen

- Has a history of exertional heat stroke

- Has a history of cardiac compromise or sudden collapse

- Has a recent history of concussion or head injury.

Weather forecast: The current and forecast ambient temperature, Wet Bulb global temperature (based on heat/ humidity/wind) and risk of lightning/thunderstorms must be stated with a discussion of whether this is likely or possible to exceed thresholds which could result in special conditions or cancellation.

Emergency plan and signals: All present should confirm the location of all medical areas (players and crowd), ambulance access point and emergency on-field signals to be used.

\section{REFERENCES}

1. Semsarian C, Sweeting J, Ackerman M. Sudden cardiac death in athletes. BMJ 2015;350:h1218.

2. Drezner JA, Ackerman MJ, Anderson J, Ashley E, Asplund CA, Baggish AL, et al. Electrocardiographic interpretation in athletes: the "Seattle criteria". Br J Sports Med 2013;47(3): 122-124.

3. Maron B. Hypertrophic cardiomyopathy and other causes of sudden cardiac death in young competitive athletes, with considerations for preparticipation screening and criteria for disqualification. Cardiol Clin 2007;25(3):399-414.

4. Corrado D, Basso C, Rizzoli G, Schiavon M, Thiene G. Does sports activity enhance the risk of sudden death in adolescents and young adults? J Am College of Cardiol 2003;42(11):1959-1963.

5. Borjesson M, Serratosa L, Carre F, Corrado D, et al. Consensus document regarding cardiovascular safety at sports arenas. Position stand from the European Association of Cardiovas- 
cular Prevention and Rehabilitation, section of Sports Cardiology. Europ Heart J 2011;32(17):2119-2124.

6. Holst A, Winkel B, Theilade J, Kristensen I, Thomsen J, Ottesen $\mathrm{G}$, et al. Incidence and etiology of sports-related sudden cardiac death in Denmark-implications for preparticipation screening. Heart Rhythm 2010;7(10):1365-1371.

7. Risgaard $B$, Winkel B, Jabbari R, Glinge C, Ingemann-Hansen $\mathrm{O}$, Thomsen J, et al. Sports-related sudden cardiac death in a competitive and a noncompetitive athlete population aged 12 to 49 years: data from an unselected nationwide study in Denmark. Heart Rhythm 2014;11(10):1673-1681.

8. Siscovick D, Weiss N, Fletcher R, Lasky T. The incidence of primary cardiac arrest during vigorous exercise. New England J Med 1984;311(14):874-877.

9. Young M, Fricker P, Thomson N, Lee K. Sudden death due to ischaemic heart disease in young aboriginal sportsmen in the Northern Territory, 1982-1996. Med J Aust 1999;170(9):425-428.

10. Position Statement: Pre-participation Cardiac Evaluation In Young Athletes. (ACSP) ACoSP. 20132013.

11. ECB. ECB Sports Science and Medicine Team. Available at: http:/ / www.ecb.co.uk/ecb/national-cricket-performancecentre/sports-science-medicine-team; 2015 [cited Accessed September 11, 2015].

12. Corrado D, Drezner J, Basso C, Pelliccia A, Thiene G. Strategies for the prevention of sudden cardiac death during sports. Europ J Cardiovasc Prevention Rehab 2011;18(2):197-208.

13. Futterman LG, Myerburg R. Sudden death in athletes: an update. Sports Med 1998;26(5):335-350.

14. Davogustto G, Higgins J. Sudden cardiac death in the soccer field: a retrospective study in young soccer players from 2000 to 2013. Physician and Sportsmedicine 2014;42(4):20-29. PubMed PMID: 25419885.

15. Drezner JA, Dvorak J, Kramer EB, Mandelbaum B, Patricios J, Pedrinelli LF, et al. The FIFA 11 Steps to prevent sudden cardiac death during football games. Europ Heart J 2013;34(47):3594-3595.

16. Schmied C, Drezner J, Kramer E, Dvorak J. Cardiac events in football and strategies for first-responder treatment on the field. Br J Sports Med 2013;47(18):1175-1178.

17. Mitchell JH, Haskell W, Snell P, Van Camp SP. Task Force 8: classification of sports. J Am College of Cardiol 2005;45(8): 1364-1367.

18. Joseph C, Finch C. The incidence of injury in Australian community level cricket players: A national overview of insurance claims from 2004-2013. In: Ferdinands R, editor. 5th World Conference of Science and Medicine in Cricket; North Sydney: University of Sydney; 2015. p. 41.

19. D'Silva A, Papadakis M. Sudden cardiac death in athletes. Europ Cardiol Rev 2015;10(1):48-53.

20. Drezner J, Rao A, Heistand J, et al. Effectiveness of emergency response planning for sudden cardiac arrest in United States high schools with automated external defibrillators. Circulation 2009;120(6):518-525.

21. Kramer EB. Automated external defibrillator in sport: absolutely always available. Brit J Sports Med 2013;47(18):1138.

22. Toresdahl B, Courson R, Borjesson M, Sharma S, Drezner J. Emergency cardiac care in the athletic setting: from schools to the Olympics. Brit J Sports Med 2012;46(Suppl 1):i85-89.

23. Wassertheil J, Keane G, Fisher N, Leditschke J. Cardiac arrest outcomes at the Melbourne Cricket Ground and Shrine of Remembrance using a tiered response strategy-a forerun- ner to public access defibrillation. Resuscitation 2000;44(2): 97-104.

24. Darke S, Torok M, Duflou J. Sudden or unnatural deaths involving anabolic-androgenic steroids. J Forensic Sci 2014;59(4): 1025-1028.

25. Montagnana M, Lippi G, Franchini M, Banfi G, Guidi GC. Sudden cardiac death in young athletes. Intern Med 2008; 47(15):1373-1378.

26. O'Connor FG, Meyering CD, Patel R, Oriscello RP. Joint National Committee on the Prevention DE, Treatment of High Blood P. Hypertension, athletes, and the sports physician: implications of JNC VII, the Fourth Report, and the 36th Bethesda Conference Guidelines. Current Sports Med Reports 2007;6(2):80-84.

27. Anderson JB, Grenier M, Edwards NM, Madsen NL, Czosek RJ, Spar DS, et al. Usefulness of combined history, physical examination, electrocardiogram, and limited echocardiogram in screening adolescent athletes for risk for sudden cardiac death. Am J Cardiol 2014;114(11):1763-1767.

28. Bar-Cohen Y, Silka MJ. The presports cardiovascular evaluation: should it depend on the level of competition, the sport, or the state? Pediatr Cardiol 2012;33(3):417-427.

29. Coris EE, Sahebzamani F, Curtis A, Jennings J, Walz SM, Nugent D, et al. Preparticipation cardiovascular screening among National Collegiate Athletic Association Division I Institutions. Br J Sports Med 2013;47(3):182-184.

30. Corrado D, Pelliccia A, Bjornstad HH, Vanhees L, Biffi A, Borjesson $\mathrm{M}$, et al. Cardiovascular preparticipation screening of young competitive athletes for prevention of sudden death: proposal for a common European protocol. Consensus Statement of the Study Group of Sport Cardiology of the Working Group of Cardiac Rehabilitation and Exercise Physiology and the Working Group of Myocardial and Pericardial Diseases of the European Society of Cardiology. Europ Heart J 2005;26(5):516-524.

31. Drezner J, Corrado D. Is there evidence for recommending electrocardiogram as part of the pre-participation examination? Clin J Sport Med 2011;21(1):18-24.

32. Magalski A, McCoy M, Zabel M, Magee LM, Goeke J, Main ML, et al. Cardiovascular screening with electrocardiography and echocardiography in collegiate athletes. Am J Med 2011;124(6):511-518.

33. Thunenkotter T, Schmied C, Dvorak J, Kindermann W. Benefits and limitations of cardiovascular precompetition screening in international football. Clin Res Cardiol 2010;99(1):29-35.

34. Corrado D, Basso C, Pavei A, Michieli P, Schiavon M, Thiene G. Trends in sudden cardiovascular death in young competitive athletes after implementation of a preparticipation screening program. JAMA 2006;296(13):1593-1801.

35. Maron B, Haas T, Doerer J, Thompson P, Hodges J. Comparison of U.S. and Italian experiences with sudden cardiac deaths in young competitive athletes and implications for preparticipation screening strategies. Am J Cardiol 2009;104(2):276-280.

36. Steinvil A, Chundadze T, Zeltser D, Rogowski O, Halkin A, Galily Y, et al. Mandatory electrocardiographic screening of athletes to reduce their risk for sudden death proven fact or wishful thinking? J Am Coll Cardiol 2011;57(11):1291-1296.

37. Womack J. Sudden Cardiac Death in Athletes: Is Universal ECG Screening Plausible? Asian J Sports Med 2011;2(2): 117-119. 
38. Uberoi A, Froelicher F. Sudden Cardiac Death in Athletes: Big Trouble, Not So Little Asia. Asian J Sports Med 2011;2(4): 275-276.

39. Millar L, Sheikh N, Sharma S. Clinical and Genetic Aspects of Sudden Cardiac Death in the Practice of Sports Medicine. Colloquium Series on Genomic and Molecular Medicine 2012:162 pages, (doi:10.4199/C00062ED1V01Y201206GMM002).

40. Alattar A, Maffulli N. The validity of adding ecg to the preparticipation screening of athletes an evidence based literature review. Transl Med UniSa 2014 Dec 19;11:2-13.

41. Halabchi F, Seif-Barghi T, Mazaheri R. Sudden Cardiac Death in Young Athletes; a Literature Review and Special Considerations in Asia. Asian J Sports Med 2011;2(1):1-15.

42. Rani D, Dhandapany P, Nallari P, Narasimhan C, Thangaraj K. A Novel Arginine to Tryptophan (R144W) Mutation in Troponin T (cTnT) Gene in an Indian Multigenerational Family with Dilated Cardiomyopathy. PLoS ONE. 2014;9(7):e101451.

43. Frick M, Pachinger O, Polzl G. Myocarditis and sudden cardiac death in athletes. Diagnosis, treatment and prevention. Herz 2009;34(4):299-304.

44. Maron BJ, Doerer JJ, Haas TS, Estes NA, Hodges JS, Link MS. Commotio cordis and the epidemiology of sudden death in competitive lacrosse. Pediatr 2009;124(3):966-971.

45. Maron B, Ahluwalia A, Haas T, Semsarian C, Link M, Estes N. Global epidemiology and demographics of commotio cordis. Heart Rhythm 2011;8(12):1969-1971.

46. Sadler D. Commotio cordis: sudden death due to chest wall impact in sports (letter). Heart 1999;82(4):534.
47. Doerer J, Haas T, Estes N, Link M, Maron B. Evaluation of chest barriers for protection against sudden death due to commotio cordis. Am J Cardiol 2007;99:857-859.

48. Viano D, Bir C, Cheney A, Janda D. Prevention of commotio cordis in baseball: an evaluation of chest protectors. J Trauma 2000;49(6):1023-1028.

49. Weinstock J, Maron B, Song C, Mane P, Estes N, Link M. Failure of commercially available chest wall protectors to prevent sudden cardiac death induced by chest wall blows in an experimental model of commotio cordis. Pediatr 2006;117(4):e656-e662.

50. Maron B, Estes N. Commotio cordis. New England J Med 2010;362(10):917-927.

51. Link MS, Maron BJ, Wang PJ, Pandian NG, VanderBrink BA, Estes NA 3rd. Reduced risk of sudden death from chest wall blows (commotio cordis) with safety baseballs. Pediatr 2002;109(5):873-877.

52. Makdissi M, Brukner P. Recommendations for lightning protection in sport. Med J Aust 2002;177(1):35-37.

53. Mansingh A. West Indies: Medical coverage in WI cricket, the facilities and mechanism of coverage in W Indies. In: Dhillon M, Ferdinands R, editors. 5th World Conference of Science and Medicine in Cricket Preconference orthopaedic workshop; North Sydney:University of Sydney; 2015. p. Also, see moreat: http://www. espncricinfo.com/westindies/content/story/132767.html.

54. Ilic D, Neuberger M, Djulbegovic M, Dahm P. Screening for prostate cancer. Cochrane Database Syst Rev 2013: CD004720. 